\title{
Effectiveness of Treatment of Chronic Viral Hepatitis C by Direct-Acting Antivirals in Togo
}

\author{
Laté Mawuli Lawson-Ananissoh ${ }^{1}$, Aklesso Bagny1, Oumboma Bouglouga², Laconi Kaaga1, \\ Rafiou El-Hadji Yakoubou1, Lidaw Kogoe', Datouda Redah' ${ }^{1}$
}

\author{
${ }^{1}$ Hepatogastroenterology Unit, University Hospital Campus, Lomé, Togo \\ ${ }^{2}$ Hepatogastroenterology Unit, University Hospital of Kara, Kara, Togo \\ Email: *lawsonprosper@yahoo.fr
}

How to cite this paper: Lawson-Ananissoh, L.M., Bagny, A., Bouglouga, O., Kaaga, L., Yakoubou, R.El-H., Kogoe, L. and Redah, D. (2019) Effectiveness of Treatment of Chronic Viral Hepatitis C by Direct-Acting Antivirals in Togo. Open Journal of Gastroenterology, 9, 125-133.

https://doi.org/10.4236/ojgas.2019.97015

Received: May 9, 2019

Accepted: July 7, 2019

Published: July 10, 2019

Copyright $\odot 2019$ by author(s) and Scientific Research Publishing Inc. This work is licensed under the Creative Commons Attribution International License (CC BY 4.0).

http://creativecommons.org/licenses/by/4.0/

\begin{abstract}
Background: Viral hepatitis $\mathrm{C}$ is the second leading cause of hepatocellular carcinoma after hepatitis B in Africa and Togo in particular. The advent of direct acting antivirals has revolutionized the care and prognosis of patients infected with hepatitis C virus (HCV). Objective: To evaluate the sustained virological response (SVR) 12 weeks after oral treatment without interferon in HCV infected patients with genotypes 1 and 2. Patients and Method: Descriptive and analytical study based on the retrospective collection of data in the hepatogastroenterology unit of the University Hospital Campus of Lome (Togo) from July 11, 2016 to April 22, 2018. All patients who had a chronic viral hepatitis $\mathrm{C}$ with viral replication, naive, regardless of the genotype, regardless of the degree of liver fibrosis, and who had completed their treatment with direct-acting antivirals were included. Results: We recruited 84 patients, 60 of whom were infected with HCV genotype $2(71.43 \%)$ and 24 with HCV genotype 1 (28.57\%). There were 58 men and 26 women (sex ratio: 0.45). In HCV genotype 1 patients, the median age was 54.29 years and Sofosbuvir/Ledipasvir was the most used combination (62.50\%). In HCV genotype 2 patients, the median age was 54.5 years and Sofosbuvir associated with Ribavirin was the most used treatment $(81.66 \%)$. The virological response at the end of treatment was 100\% (genotype 1) and $93.30 \%$ (genotype 2). The SVR 12 was 100\% (genotype 1) and 91.70\% (genotype 2). Five patients were in treatment failure (genotype 2). Conclusion: Direct-acting antivirals were effective in our patients. The rate of sustained virological response was above $90 \%$.
\end{abstract}

\section{Keywords}

Viral Hepatitis C, Direct-Acting Antivirals, Sustained Virological Response, Togo 


\section{Introduction}

The World Health Organization (WHO) estimates that 170 to 180 million people are infected with the hepatitis C virus (HCV) [1]. The epidemic mainly concerns countries with limited resources where access to screening and treatment remains very inadequate. While America and Europe have 31.5 million infected people, Africa and Asia have 111 million. In Africa, the prevalence is estimated at 3\% [2]. Nevertheless, the figures vary considerably between the different mainland regions, with Central Africa having the highest prevalence estimated at $6 \%$ compared to $1.6 \%$ in South and East Africa and 2.4\% in West Africa. [2] [3]. Egypt has the highest prevalence of HCV in the world estimated at $14.5 \%$ in the 15 - 59 age group [4]. In Togo, the seroprevalence of HCV is estimated at $6.5 \%$ [5]. HCV infection is the second leading cause of hepatocellular carcinoma (HCC) after hepatitis B in Africa and Togo in particular [6]. The advent of new antiviral agents has revolutionized the care and prognosis of patients infected with HCV. Thanks to the excellent efficacy and the very good tolerance of direct antivirals, the care of patients infected with HCV in Africa is easier. To date, there are no data available on the effectiveness of new direct-acting antivirals (DAAs) in Togo. The aim of our study was to evaluate the sustained virological response (SVR) 12 weeks after oral treatment without interferon in HCV infected patients with genotypes 1 and 2 .

\section{Patients and Method}

It was a descriptive study based on the retrospective collection of data in the hepatogastroenterology unit of the University Hospital Campus of Lome (Togo) from July 1, 2016 to May 31, 2018. The study population consisted of all patients who had a chronic viral $\mathrm{C}$ infection with viral replication, naive, regardless of the genotype, regardless of the degree of liver fibrosis, and having been placed under direct-acting antivirals. Were included, patients who had completed their treatment with DAAs.

\section{Definition of Virological Responses}

Virological responses to treatment were defined as follows:

- RVR (rapid virological response): Undetectable HCV-RNA after 4 weeks of treatment.

- Virologic response at the end of treatment: Undetectable HCV-RNA after 12 weeks of treatment.

- SVR12 (Sustained Virologic Response): HCV-RNA undetectable at 12 weeks after stopping treatment.

\section{Parameters Studied}

Have been studied in our study:

1) Patient's characteristics at inclusion

- Epidemiological characteristics: age and gender. 
- Virological markers: viral genotype C, viremia in UI/ml and Log UI. Viremia was performed in the CERBA laboratory in Paris, France. The detection threshold for viremia was $15 \mathrm{IU} / \mathrm{ml}$, i.e. $1.2 \mathrm{Log}$, HIV status, total HBsAg and Ac anti-HBc.

- Hepatopathy information: hepatic ultrasound, Transaminases (AST and ALT in UI/l: hepatic cytolysis was defined by AST or ALT > 1.5 times the upper limit of normal (ULN), hemogram, prothrombin rate, APRI score (a score $>2$ at the start of treatment was considered a hepatopathy marker at cirrhosis stage [7]), FIB-4 score (a score $>3.25$ at the beginning of treatment was considered a marker of severe fibrosis [8]), Actitest-Fibrotest. The METAVIR score was based on a blood test (Fibrotest). No liver biopsy was performed in our patients.

- Treatment with DAAs: the drugs used were: Sofosbuvir $400 \mathrm{mg}$ (SFV) combined with Ribavirin (1000 mg if the patient's weight $<75 \mathrm{~kg}$ and $1200 \mathrm{mg}$ if the patient's weight $\geq 75 \mathrm{~kg}$ ) (RBV) or Sofosbuvir $400 \mathrm{mg}$ combined with Ledipasvir $90 \mathrm{mg}$ (LDV) in fixed combination with or without Ribavirin (1000 $\mathrm{mg}$ if the patient's weight $<75 \mathrm{~kg}$ and $1200 \mathrm{mg}$ if the patient's weight $\geq 75 \mathrm{~kg}$ ) or Sofosbuvir $400 \mathrm{mg}$ combined with Daclatasvir $60 \mathrm{mg}$ (LDV) with or without Ribavirin $(1000 \mathrm{mg}$ if the patient's weight $<75 \mathrm{~kg}$ and $1200 \mathrm{mg}$ if the patient's weight $\geq 75 \mathrm{~kg}$ ).

2) Follow-up for evaluation of the effectiveness of treatment

- During treatment, monitoring of transaminases and viral load $\mathrm{C}$ at inclusion, S4 and at the end of treatment (in case of detectable viral load at S4, monthly monitoring could be done until viro-suppression). We specified the RVR rate and the virological response rate at the end of treatment.

- After the end of treatment, monitoring of transaminases and viral load C 12 weeks after the end of treatment. We have specified the rate of SVR 12.

\section{Data Entry and Clearance}

At the end of the collection, the cards were entered into a database designed under the Epidata software version 3.1.

\section{Statistical Analysis}

Statistical analysis was performed with the R Studio software version 3.4.2. It included a descriptive analysis of the population and a comparative analysis. In the descriptive analysis for the characteristics collected (socio-demographic characteristics, biological and clinical characteristics), the results were expressed in terms of size and percentage for the qualitative variables or mean and standard deviation for the quantitative variables (or median and interquartile range depending on the choice which was made). In terms of comparative analysis, the statistical tests used were the Pearson Chi-square test or the Fisher exact test for qualitative variables and the Student's test for quantitative variables or the Wilcoxon non-parametric series test. In the comparative analysis we looked at each genotype (genotypes 1 and 2), a relationship between all the variables collected 
according to the detectability.

\section{Ethical Considerations}

Data collection was retrospective. However, at the initiation of this study, patients were informed on the objectives of the study and gave their consent. Anonymity was respected when collecting data.

\section{Results}

\subsection{General Characteristics of Patients}

We recruited 84 patients, 60 of whom were infected with HCV genotype 2 (71.43\%) and 24 with HCV genotype 1 (28.57\%). There were 58 men and 26 women (sex ratio: 0.45 ). All patients were naive to any previous antiviral $\mathrm{C}$ treatment. HIV retroviral serology and the search for HBsAg were negative in all patients.

\subsection{Characteristics of Patients Infected with HCV Genotype 1}

Of the 24 patients, there were 16 men and 8 women (Table 1). The median age was 54.29 with an interquartile range (IQR) of 46.25 years to 64 years. SFV/LDV was the most used combination (62.50\%). The mean value of HCV-RNA at inclusion in the study was $3,111,701 \mathrm{IU} / \mathrm{ml}$ with extremes of $4210 \mathrm{IU} / \mathrm{ml}$ to 15,600,000 IU/ml. Three patients had F4 fibrosis Fibrotest. Hepatic cytolysis was noted in 13 patients. Thrombocytopenia was found in 8 patients.

\subsection{Characteristics of Patients Infected with HCV Genotype 2}

Of the 60 patients, there were 42 men and 18 women (Table 1 ). The median age was 54.5 years with an interquartile range (IQR) of 45.75 to 61 years. SFV associated with RBV was the most used antiviral treatment (81.66\%). The mean value of HCV-RNA at inclusion in the study was $27,910,000 \mathrm{IU} / \mathrm{ml}$ with extremes of 4210 to $1,480,000,000 \mathrm{IU} / \mathrm{ml}$. Eleven patients had F4 fibrosis at Fibrotest. Hepatic cytolysis was noted in 35 patients. Thrombocytopenia was found in 19 patients.

\subsection{Therapeutic Effectiveness}

For patients infected with HCV genotype 1, the RVR was $100 \%$ and the virological response at the end of treatment was 100\%; the SVR 12 was 100\% (Figure 1). For patients infected with HCV genotype 2, the RVR was $100 \%$ and the virological response at the end of treatment was $93.30 \%$; SVR 12 was $91.70 \%$ (Figure 1). In these genotype $2 \mathrm{HCV}$-infected patients, the median age $(\mathrm{p}=0.883)$, gender $(p=0.61)$, median viral load $C$ at inclusion $(p=0.097)$, presence of significant fibrosis at Fibrotest $(\mathrm{p}=0.341)$, FIB-4 $(\mathrm{p}=0.380)$, APRI score $(\mathrm{p}=$ 0.528 ) were not significantly associated with SVR12.

\subsection{Treatment Failure}

Five patients were in treatment failure (Table 2); these were genotype 2 patients 
who were all on SFV/RBV (8.33\%). These 5 patients who failed treatment had a viral load $>5$ log on inclusion; among them, one had an undetectable viral load at the end of treatment and it was at 3 months after the end of treatment that the viral load became detectable at 6.08 log. No patient infected with HCV genotype 1 failed treatment.

Table 1. Patients characteristics at inclusion.

\begin{tabular}{|c|c|c|}
\hline & Genotype $1(\mathrm{n}=24)$ & Genotype $2(n=60)$ \\
\hline \multicolumn{3}{|l|}{ Epidemiological parameters } \\
\hline \multicolumn{3}{|l|}{ Gender } \\
\hline Male & $16(66.67)$ & $42(70)$ \\
\hline Female & $8(33.33)$ & $18(30)$ \\
\hline Age in years: median (IQR) & $54.29(46.25-64)$ & $54.5(45.75-61)$ \\
\hline \multicolumn{3}{|l|}{ Direct-acting antivirals used } \\
\hline SFV/LDV n (\%) & $15(62.50)$ & $0(0)$ \\
\hline SFV/DCV n (\%) & $8(33.33)$ & $10(16.67)$ \\
\hline SFV/RBV n (\%) & $0(0)$ & $49(81.66)$ \\
\hline SFV/DCV/RBV n (\%) & $1(4.17)$ & $1(1.67)$ \\
\hline \multicolumn{3}{|l|}{ Virological markers } \\
\hline HCV RNA in UI/ml: median (IQR) & $813,221(281,561-3,111,701)$ & $688,600(233,000-4,792,000)$ \\
\hline HCV RNA in log: median (IQR) & $5.895(5.450-6.423)$ & $5.830(5.265-6.680)$ \\
\hline \multicolumn{3}{|l|}{ Hepatopathy information } \\
\hline Cirrhosis (Fibrosis F4): n (\%) & $3(12.50)$ & $11(18.33)$ \\
\hline \multicolumn{3}{|l|}{ Methods for assessing fibrosis } \\
\hline FIB-4: n (\%) & $24(100)$ & $57(95)$ \\
\hline FIB-4: median (IQR) & $2.625(1.360-3.5530)$ & $2.370(1.260-4.590)$ \\
\hline APRI: n (\%) & $24(100)$ & $57(95)$ \\
\hline APRI: median (IQR) & $0.855(0.4475-1.4125)$ & $0.99(0.61-2.260)$ \\
\hline Fibrotest: n (\%) & $20(83.33)$ & $50(83.33)$ \\
\hline AST (UI/l): median (IQR) & $52(34-83)$ & $56(40-104.8)$ \\
\hline ALT (UI/l): median (IQR) & $66(33.75-85.25)$ & $66.5(40-104.8)$ \\
\hline \multicolumn{3}{|l|}{ Biological parameters: median (IQR) } \\
\hline Platelets $\left(/ \mathrm{mm}^{3}\right)$ & $172.5(131.8-213.5)$ & $168(133-200)$ \\
\hline Neutrophil $\left(/ \mathrm{mm}^{3}\right)$ & $1650(1245-2612)$ & $1894(1462-2294)$ \\
\hline Haemoglobin (g/dl) & $12.7(11.22-13.55)$ & $13.3(12.05-14.80)$ \\
\hline
\end{tabular}

IQR: Interquartile range, SFV: Sofosbuvir; LDV: Ledipasvir; RBV: Ribavirin; DCV: Daclatasvir. 
Table 2. Characteristics of patients in treatment failure.

\begin{tabular}{ccccccc}
\hline Genotype & Gender & $\begin{array}{c}\text { Age } \\
\text { (years) }\end{array}$ & Cirrhosis & $\begin{array}{c}\text { HCV RNA } \\
(\log \mathrm{UI})\end{array}$ & $\begin{array}{c}\text { Drugs } \\
\text { used }\end{array}$ & $\begin{array}{c}\text { Time of } \\
\text { treatment failure }\end{array}$ \\
\hline 2 & 2 & 62 & NO & 5.27 & SFV/RBV & End of treatment \\
2 & 1 & 66 & NO & 7.35 & SFV/RBV & End of treatment \\
2 & 1 & 48 & NO & 6.87 & SFV/RBV & End of treatment \\
2 & 1 & 38 & NO & 7.24 & SFV/RBV & End of treatment \\
2 & 1 & 55 & NO & 6 & SFV/RBV & $\begin{array}{c}12 \text { weeks after the } \\
\text { end of treatment }\end{array}$ \\
\hline
\end{tabular}

SFV: Sofosbuvir; RBV: Ribavirin.

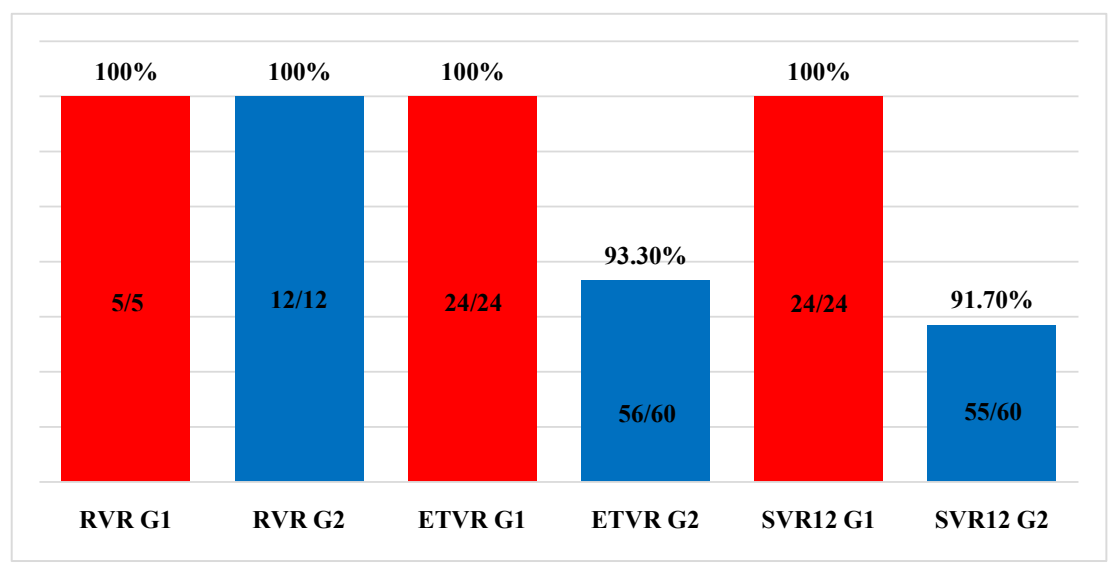

RVR: Rapid virological response ETVR: End of treatment virological response SVR: Sustained virological response G1: Genotype 1 (red) G2: Genotype 2 (blue)

Figure 1. Virological responses in patients infected by hepatitis $C$ virus genotypes 1 and 2 .

\section{Discussion}

The main limitation of our study is the relatively small size of our sample, which could be explained by the financial difficulty of patients in paying direct acting antivirals. However, our study has noted the effectiveness of these drugs in the treatment of patients with chronic viral hepatitis $\mathrm{C}$ in Togo. In our study, the rapid virological response (RVR) was $100 \%$ for all genotypes 1 and 2 patients in whom the viral load has been achieved; the virological response at the end of treatment was $100 \%$ (genotype 1) and $93.3 \%$ (genotype 2); SVR 12 was $100 \%$ (genotype 1) and $91.7 \%$ (genotype 2). Five patients were in treatment failure either at the end of treatment (4 non-responders) or 12 weeks after the end of treatment ( 1 responder-relapser patient). These 5 patients were all genotype 2. In the Reddy et al. [9] study, 513 patients infected with HCV genotype 1 (161 naïve and cirrhotic patients) were treated for 12 or 24 weeks with Sofosbuvir/Ledipasvir with or without ribavirin. The SVR rate was $96 \%$, without influence of duration of treatment or combination with ribavirin. In the American cohort [10], 1014 non-cirrhotic naïve patients with low viral load were treated with Sofosbuvir/Ledipasvir for 8 weeks; SVR was $93 \%$ comparable to that 
seen in 808 patients treated for 12 weeks (96\%). In the TARGET study [11], 674 naive patients (38\% cirrhotic patients) were treated with Sofosbuvir/Ledipasvir for 8 to 24 weeks (40 patients had received ribavirin additionally); SVR was $96 \%$. In 323 non-cirrhotic naïve patients with a viral load <6,000,000 IU/ml, 131 patients and 192 patients were treated for 8 and 12 weeks respectively; SVR was $97 \%$ in both groups. These results favored treatment with Sofosbuvir/Ledipasvir for 8 weeks in naïve patients without cirrhosis with a viremia $<6,000,000 \mathrm{IU} / \mathrm{ml}$ and for 12 weeks in other patients. The current recommended treatment for genotype $1 \mathrm{HCV}$ is Sofosbuvir/Velpatasvir or Sofosbuvir/Ledipasvir. At the time of inclusion of patients in this study, the treatments available in Togo for HCV genotype 1 were Sofosbuvir/Ledipasvir and Sofosbuvir/Daclatasvir. In our study, $63 \%$ of patients infected with $\mathrm{HCV}$ genotype 1 were put under Sofosbuvir/Ledipasvir and 37\% were put under Sofosbuvir/Daclatasvir. The cure rate was $100 \%$. This reflects the effectiveness of direct acting antivirals. In the case of genotype $2 \mathrm{HCV}$, the current recommended treatment is Sofosbuvir/Velpatasvir. At the time of recruitment of patients in our present study, the molecules available in Togo in case of genotype 2 viral C infection were Sofosbuvir/Ribavirin or Sofosbuvir/Daclatasvir. In our study, $81.6 \%$ of patients infected with HCV genotype 2 were treated with Sofosbuvir/Ribavirin and $16.7 \%$ with Sofosbuvir/Daclatasvir. In the VALENCE trial [12], SVR after 12 weeks of treatment with Sofosbuvir/Ribavirin was 93\% (68/73); SVR was 94\% (59/63) in non-cirrhotic patients and $82 \%$ in patients with cirrhosis; SVR was $97 \%(29 / 30)$ in non-cirrhotic naïve patients, $100 \%(2 / 2)$ in cirrhotic naïfs, $94 \%(30 / 32)$ in non-cirrhotic pretreated and 78\% (7/9) in cirrhotic pretreated. In the Omata et al. [13] study in Japan, 90 naïve patients and 63 pre-treated patients infected with HCV genotype 2 were treated with Sofosbuvir/Ribavirin for 12 weeks. Of the 90 naïve patients, the SVR was $98 \%$. Of the 63 pretreated patients, SVR was $95 \%$. The SVR rate was $94 \%$ in cirrhotic patients. In the literature, irrespective of genotype, elevated viremia, cirrhosis, and failure of previous antiviral $\mathrm{C}$ treatment were the main failure factors in responder-relapse patients [14] [15]. In our study, no virological or biological factors were associated with SVR 12; the small size of our sample could explain it. In the event of failure of DAA therapy, it is recommended to document poor treatment adherence, drug interactions and intercurrent pathologies that may interfere with the absorption of DAAs. A non-optimal therapeutic scheme or premature discontinuation of treatment should be sought.Viral re-infection must also be ruled out [16]. If none of the above-mentioned causes of treatment failure are found in case of failure of direct antiviral agent treatment, it is recommended to evaluate the resistance mutations before deciding on the new therapeutic line [16]. In our study, we believe that poor observation of treatment may explain this failure. It is true that ribavirin is no longer in the forefront of current recommendations for the treatment of chronic viral C infection [16] [17] [18]. However, in resource-limited countries like Togo, where availability and accessibility of DAAs are difficult given their high cost, Sofosbuvir/Ribavirin (less expensive) could be used if there is no con- 
traindication to the use of ribavirin. However it is necessary to prioritize treatment protocol without ribavirin.

\section{Conclusion}

Direct-acting antivirals have revolutionized the management of viral hepatitis $\mathrm{C}$ in the world and in Togo in particular. These drugs offer the possibility of oral therapy without interferon. This study could be extended to include a large number of patients to look for clinical, virological, and biological factors associated with SVR 12

\section{Conflicts of Interest}

The authors declare no conflicts of interest regarding the publication of this paper.

\section{References}

[1] Lavanchy, D. (2011) Evolving Epidemiology of Hepatitis C Virus. Clinical Microbiology and Infection, 17, 107-115. https://doi.org/10.1111/j.1469-0691.2010.03432.x

[2] Madhava, V., Burgess, C. and Drucker, E. (2002) Epidemiology of Chronic Hepatitis C Virus Infection in Sub-Saharan Africa. The Lancet Infectious Diseases, 2, 293-302. https://doi.org/10.1016/S1473-3099(02)00264-5

[3] Mohd Hanafiah, K., Groeger, J., Flaxman, A.D. and Wiersma, S.T. (2013) Global Epidemiology of Hepatitis C Virus Infection: New Estimates of Age-Specific Antibody to HCV Seroprevalence. Hepatology, 57, 1333-1342. https://doi.org/10.1002/hep.26141

[4] Yousra, A.M., Ghina, R.M., Riome, S., De Wolfe, M. and Laith, J.A.-R. (2013) The Epidemiology of Hepatitis C Virus in Egypt: A Systematic Review and Data Synthesis. BMC Infectious Diseases, 13, 288. https://doi.org/10.1186/1471-2334-13-288

[5] Bagny, A., Bouglouga, O., Djibril, M., Lawson, A., Kaaga, Y.L., Sama Hamza, D., et al. (2013) Knowledge, Attitudes and Practices Relative to the Risk of Transmission of Hepatitis B and C Viruses in a Hospital in Togo. Médecine et Santé Tropicales, 23, 300-303.

[6] Kirk, G.D., Lesi, O.A., Mendy, M., Akano, A.O., Sam, O., Goedert, J.J., et al. (2004) The Gambia Liver Cancer Study: Infection with Hepatitis B and C and the Risk of Hepatocellular Carcinoma in West Africa. Hepatology, 39, 211-219. https://doi.org/10.1002/hep.20027

[7] Wai, C.T., Greenson, J.K., Fontana, R.J., Kalbfleisch, J.D., Marrero, J.A., Conjeevaram, H.S., et al. (2003) A Simple Noninvasive Index Can Predict Both Significant Fibrosis and Cirrhosis in Patients with Chronic Hepatitis C. Hepatology, 38, 518-526. https://doi.org/10.1053/jhep.2003.50346

[8] Sterling, R.K., Lissen, E., Clumeck, N., Sola, R., Correa, M.C., Montaner, J., et al. (2006) Development of a Simple Noninvasive Index to Predict Significant Fibrosis in Patients with HIV/HCV Coinfection. Hepatology, 43, 1317-1325. https://doi.org/10.1002/hep.21178

[9] Reddy, K., Bourlière, M., Sulkowski, M., Omata, M., Zeuzem, S., Feld, J.J., et al. 
(2015) Ledipasvir and Sofosbuvir in Patients with Genotype 1 Hepatitis C Virus Infection and Compensated Cirrhosis: An Integrated Safety and Efficacy Analysis. Hepatology, 62, 79-786. https://doi.org/10.1002/hep.27826

[10] Backus, L., Belperio, P., Shahoumian, T.A., Loomis, T. and Mole, L. (2015) Effectiveness of Ledipasvir/Sofosbuvir in Treatment Naïve Genotype 1 Patients Treated in Routine Medical Practice. Hepatology, 62, 255A.

[11] Terrault, N., Zeuzem, S., di Bisceglie, A.M., Lim, J., Pockros, P., Frazier, L., et al. (2015) Treatment Outcomes with 8, 12 and 24 Weeks Regimens of Ledipasvir/Sofosbuvir for the Treatment of Hepatitis C Infection: Analysis of a Multicenter Prospective, Observational Study. Hepatology, 62, 256A.

[12] Zeuzem, S., Dusheiko, G.M., Salupere, R., Mangia, A., Flisiak, R., Hyland, R.H., et al. (2014) Sofosbuvir and Ribavirin in HCV Genotypes 2 and 3. The New England Journal of Medicine, 370, 1993-2001. https://doi.org/10.1056/NEJMoa1316145

[13] Omata, M., Nishiguchi, S., Ueno, Y., Mochizuki, H., Izumi, N., Ikeda, F., et al. (2014) Sofosbuvir Plus Ribavirin in Japanese Patients with Chronic Genotype 2 HCV Infection: An Open-Label, Phase 3 Trial. Journal of Viral Hepatitis, 21, 762-768. https://doi.org/10.1111/jvh.12312

[14] Osinusi, A., Meissner, E.G., Lee, Y.-J., Bon, D., Heytens, L., Amy Nelson, A., et al. (2013) Efficacy of Sofosbuvir and Ribavirin for Treatment of Hepatitis C Genotype-1 in an Inner City Population: Virus and Host Factors that Predict Relapse. The Journal of the American Medical Association, 310, 804-811. https://doi.org/10.1001/jama.2013.109309

[15] Afdhal, N., Reddy, K.R., Nelson, D.R., Lawitz, E., Gordon, S.C., Schiff, E., et al. (2014) Ledipasvir and Sofosbuvir for Previously Treated HCV Genotype 1 Infection. The New England Journal of Medicine, 370, 1483-1493. https://doi.org/10.1056/NEJMoa1316366

[16] Association Française pour l'Etude du foie (2017) Recommandations AFEF sur la prise en charge des hépatites virales $C$.

http://www.afef.asso.fr/ckfinder/userfiles/files/recommandations-textes-officiels/Re commandations_AFEF_HepatiteC_Final-02-2016.pdf

[17] American Association for the Study of Liver Diseases (AASLD) and the Infectious Diseases Society of America (2018) Hepatitis C Guidance 2018 Update: AASLD-IDSA Recommendations for Testing, Managing, and Treating Hepatitis C Virus Infection. Clinical Infectious Diseases, 67, 1477-1492.

[18] European Association for the Study of the Liver (2018) EASL Recommendations on Treatment of Hepatitis C 2018. Journal of Hepatology, 69, 461-511. 